\title{
Incidence and clinical relevance of heterotopic ossification after internal fixation of acetabular fractures: retrospective cohort and case control study
}

Dominik Baschera ${ }^{1 * \dagger}$, Hooman Rad ${ }^{1+}$, Dermot Collopy ${ }^{1}$ and René Zellweger ${ }^{1,2}$

\begin{abstract}
Objective: The aim of the study was to evaluate predictors and clinical relevance of heterotopic ossification $(\mathrm{HO})$ in patients treated for acetabular fractures in a tertiary referral centre.

Patients and methods: The study is a retrospective cohort study with a nested case-control study. All patients treated with internal fixation of acetabular fractures from January 2004 to October 2013. Ninety patients had postoperative imaging available at 6 and 12 months postoperatively and received no prophylaxis. Plain radiographs were used to grade HO. The Hip disability and Osteoarthritis Outcome Score (HOOS) was used to compare outcomes between patients suffering from $\mathrm{HO}$ with patients who did not.

Results: Sixteen patients (17.7\%) suffered from HO. According to the Brooker classification, 5 had class I, 4 class II, 3 class III and 4 class IV HO. Traumatic brain injury (TBI) was the only significant risk factor for developing $\mathrm{HO}$ (odds ratio (OR) 8.6, 95\% confidence interval $(\mathrm{Cl})(1.693-43.753), p=0.014)$. The $\mathrm{HO}$ rate in patients with an anterior (ilioinguinal) or posterior (Kocher-Langenbeck) surgical approach was 20\% and 21\% respectively, and the $\mathrm{HO}$ rate in patients with a combined approach was much lower at 11\%. Neither fracture type nor gender nor age increased the risk of $\mathrm{HO}$ significantly. The outcome measured by HOOS was not significantly different between patients with $\mathrm{HO}$ and patients in the control group. Patients with $\mathrm{HO}$ Brooker class II-IV had slightly lower (effect estimate +4.25 , $95 \% \mathrm{Cl}(-10.2$ to +12.10$), p=0.220)$ HOOS compared to the majority of the control group.

Conclusion: A very low rate of $\mathrm{HO}$ was found compared to the $\mathrm{HO}$ rates described in other studies with similar patient cohorts who received prophylaxis. Based on our findings and the current literature, we do not recommend giving prophylaxis against $\mathrm{HO}$ to patients after internal fixation of acetabular fractures.
\end{abstract}

Keywords: Acetabular fractures, Heterotopic ossification, Prophylaxis, Internal fixation, Trauma

\section{Background}

Heterotopic ossification ( $\mathrm{HO})$ in patients receiving internal fixation of acetabular fractures is a potentially disabling complication that occurs in up to $58 \%$ of cases $[1,2]$. In many centres, indomethacin or low-dose radiotherapy is administered as prophylaxis to prevent the development of $\mathrm{HO}$, although these practices are still

\footnotetext{
* Correspondence: dbaschera@bluewin.ch

${ }^{\dagger}$ Equal contributors

'Department of Orthopaedics and Trauma Surgery, Royal Perth Hospital, Perth, WA 6000, Australia

Full list of author information is available at the end of the article
}

controversial. Heterotopic ossification is a process by which the soft tissue becomes ossified. It occurs when primitive mesenchymal cells in the surrounding soft tissue are transformed into osteoblastic cells. Differentiation occurs within $16 \mathrm{~h}$ after surgery and peaks at $32 \mathrm{~h}$ [3]. The trigger for $\mathrm{HO}$ following major hip procedures is unknown, but several risk factors have been named. $\mathrm{HO}$ is commonly classified etiologically into neurogenic, musculoskeletal trauma related and hereditary. It is significantly more prevalent in patients who have sustained severe head traumas and spinal injuries. Lateral surgical approach, delay in internal fixation, diffuse idiopathic 
skeletal hyperostosis, Paget's disease and hypertrophic osteoarthritis are other factors that may contribute to developing $\mathrm{HO}$. A recent retrospective analysis found prolonged mechanical ventilation as a risk factor for developing $\mathrm{HO}$ [4]. The most common symptom of $\mathrm{HO}$ of the hip is stiffness of the joint with varying degrees of range of movement loss. Diagnosis after osteosynthesis is usually done radiographically with an anterior-posterior (AP) view of the pelvis and/or the hip. $\mathrm{HO}$ of the hip is classified using the Brooker classification grading $\mathrm{HO}$ from 1 to 4 according to the size of the bone islands in the soft tissue and their relative position to the acetabulum and the greater trochanter [5]. The only treatment option for established HO is delayed surgical resection when the heterotopic bone has matured and is encapsuled, which is approximately 6 months postoperatively [6].

In many centres, postoperative prophylaxis is administered. The type of medication and the duration of treatment recommended vary, but the most common prophylaxis is indomethacin in a $25-\mathrm{mg}$ dose, three times daily (or slow release $75 \mathrm{mg}$ once daily), for 7-14 days postoperatively, commenced within $24-48 \mathrm{~h}$ after the surgical procedure. While other non-steroidal antiinflammatory drugs (NSAIDs) were found to be effective for the prevention of $\mathrm{HO}$ following total hip replacements, indomethacin remains the only drug with evidence in preventing $\mathrm{HO}$ following acetabular surgery [7]. A recent study compared the efficacy of indomethacin given for 3 days, 7 days and 6 weeks compared to placebo and found the best results in patients prescribed indomethacin for 7 days [8]. The worst results were found in patients that received indomethacin for 6 weeks. There was no reduction of symptomatic $\mathrm{HO}$ between groups that received indomethacin and placebo group [8]. In some centres, external beam radiation in a single dose of 700 to 800 centigray (cGy) is administered as prophylaxis for HO 24-72 h postoperatively. The current literature disputes the efficacy of different types of $\mathrm{HO}$ prophylaxis in patients with acetabular fractures receiving internal fixation.

However, the beneficial effect of HO prophylaxis after fixation of acetabular fractures has never been ascertained. Both types of prophylaxis have side effects such as gastric ulcers, renal toxicity and fracture non-union from NSAIDs and malignancy for irradiation, possible benefits need to be established [9-15]. The aim of our study was to assess the rate of $\mathrm{HO}$ in a population who did not receive a prophylaxis. We also aimed to compare risk factors and functional outcomes of patients receiving internal fixation for acetabular fractures who developed $\mathrm{HO}$ with patients who did not.

\section{Patients and methods}

A retrospective study of patient notes and postoperative AP pelvic radiographs was performed for all patients documented on the theatre list for internal fixation of acetabular fractures over a 9-year period from January 2004 to October 2013. The study was approved by the Royal Perth Hospital review board. All procedures were performed in a single centre by a single surgical team. Patients that had follow-up imaging done in another hospital had to be excluded due to inaccessibility of necessary $x$-rays. The main inclusion criteria were the availability of at least two postoperative radiographs: one within 12 weeks and 6 months postoperatively during the typical period of $\mathrm{HO}$ development. Medical records were reviewed for risk factors of developing $\mathrm{HO}$ including head and spinal injuries, male sex, rheumatic diseases, interval from surgery to internal fixation and surgical approach. We also reviewed postoperative medications, in particular NSAIDs. Patients who received prophylaxis or NSAIDs postoperatively within the first $72 \mathrm{~h}$, which is the usual period of $\mathrm{HO}$ induction, were excluded from the analysis. Patients who received NSAIDs later than $72 \mathrm{~h}$ postsurgery for more than once-off pain relief were also excluded.

The Brooker classification was used to grade $\mathrm{HO}$ (Figure 1). The diagnosis was determined by postoperative plain AP view radiographs of the pelvis 1-12 months after the procedure. The definitive diagnosis was confirmed through a second opinion of an independent senior radiologist.

The patients' symptoms and functional limitations were assessed and quantified using the Hip disability and Osteoarthritis Outcome Score (HOOS) $[16,17]$. The HOOS was used to assess the functionality of patients who developed $\mathrm{HO}$ and a randomly (using excel random function) selected group of a similar size (16 rounded up to 20) of the patients who did not.

The HOOS is a questionnaire survey intended to be used to assess the patient's opinion about their hip and associated problems and to evaluate symptoms and functional limitations related to the hip [17]. The outcome score consists of 40 items assessing five subscales. The five separate patient-relevant dimensions are pain (P), symptoms (S), activity limitations daily living (ADL), function in sport and recreation (SP) and hip-related quality of life (QOL). Pain (P) includes 10 items with a total score of 40 points, symptoms (S) includes 5 items with a total score of 20 , activity limitations of daily living (ADL) includes 17 items with a total score of 68 and finally function in sport and recreation (SP) and hiprelated quality of life (QOL) both include 4 items with a total score of 16 each. Patients answered questions with the following options (0-4): no, mild, moderate, severe and extreme. To interpret the score, the outcome measure is transformed in a worst to best scale from 0 to 100, with 100 indicating no symptoms and 0 indicating extreme symptoms. To calculate the total HOOS score, the 

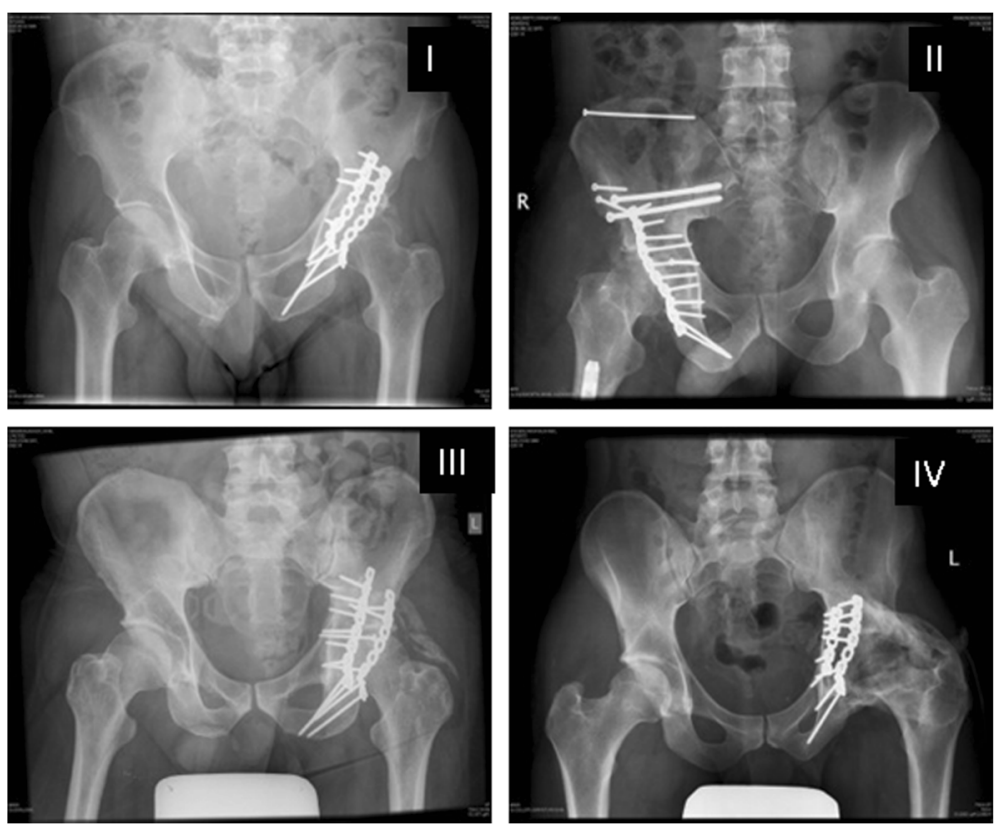

Figure 1 Different grades of heterotopic ossification according to the Brooker classification. I: X-ray of a Brooker class I heterotopic ossification (left hip): 'islands of bone within soft tissues around the hip'. II: X-ray of a Brooker class II heterotopic ossification (right hip): 'bone spurs in pelvis or proximal end of femur leaving at least $1 \mathrm{~cm}$ between the opposing bone surfaces'. III: X-ray of a Brooker class III heterotopic ossification (left hip): 'bone spurs that extend from the pelvis or the proximal end of femur, which reduce the space between the opposing bone surfaces to less than $1 \mathrm{~cm}$ '. IV: X-ray of a Brooker class IV heterotopic ossification (left hip): 'radiographic ankylosis of the hip'.

subscales need to be summed up, using the following formula for all dimensions.

$$
\begin{gathered}
100-[ \\
{[\text { patient's score of the subscale } \times \mathbf{1 0 0})} \\
\div(\text { total score of the subscale })]
\end{gathered}
$$

The subscales can be plotted as a HOOS profile, by connecting the mean scores for all five dimensions with a line [17].

\section{Statistical analysis}

All available data was analysed using SPSS - (Version 21.0). For the descriptive analysis, categorical variables like Brooker classification, gender and surgical approach were compared to each other using Fisher's exact test. To compare continuous factors like duration to internal fixation or age with the dichotomous outcome $\mathrm{HO}$, we used the Mann-Whitney $U$ test or Kruskal-Wallis test if there were more than two categories (e.g., surgical approach). The limit of significance was set to $p \leq 0.05$.

\section{Results}

Patient selection is displayed in Figure 2. The mean age of the study population was 34.6 years (14-75). The male-female ratio was 3:1. The mechanism of injury was mainly road traffic related with 56 car and 28 motorbike accidents. The remaining patients sustained injuries in falls (5) or in a skateboard accident (1). The mean interval from injury to operation/internal fixation was $7.47 \pm$ 4.38 days (range $0-19$ days). Seven (7.1\%) had also sustained concomitant traumatic brain injury (TBI) and 20 (22.2\%) had sustained a spine trauma.

Heterotopic ossification was present in 16 patients (17.7\%). According to the Brooker classification, 5 were classified as Brooker I, 4 as Brooker II, 3 as Brooker III and 4 as Brooker IV. There were no changes in grading 6 months after the trauma was sustained. The most common surgical approach was a posterior (KocherLangenbeck) approach $(n=58)$, followed by combined posterior-anterior approach $(n=27)$ and anterior (ilioinguinal) approach $(n=5)$. Similar rates of HO were found in anterior (20\%) and posterior (21\%) approaches, while patients with combined anterior-posterior approach, $\mathrm{HO}$ only developed in $11 \%$ of cases. In patients with and without $\mathrm{HO}$, the fracture types were present in similar proportions, A2-type fractures (6/37.5\% vs. 23/31.1\%) being the most frequent followed by B2-type fractures (5/31.3\% vs. $22 / 29.7 \%)$. None of the fracture types were associated with a higher risk of HO. Predictors of $\mathrm{HO}$, their prevalence and unadjusted odds ratios in the groups with and without $\mathrm{HO}$ are displayed in Tables 1 and 2.

\section{Hip disability and Osteoarthritis Outcome Score (HOOS)}

Response rate was $12 / 16$ (75\%) in the HO group and $13 / 20(65 \%)$ in the randomly selected control group. 


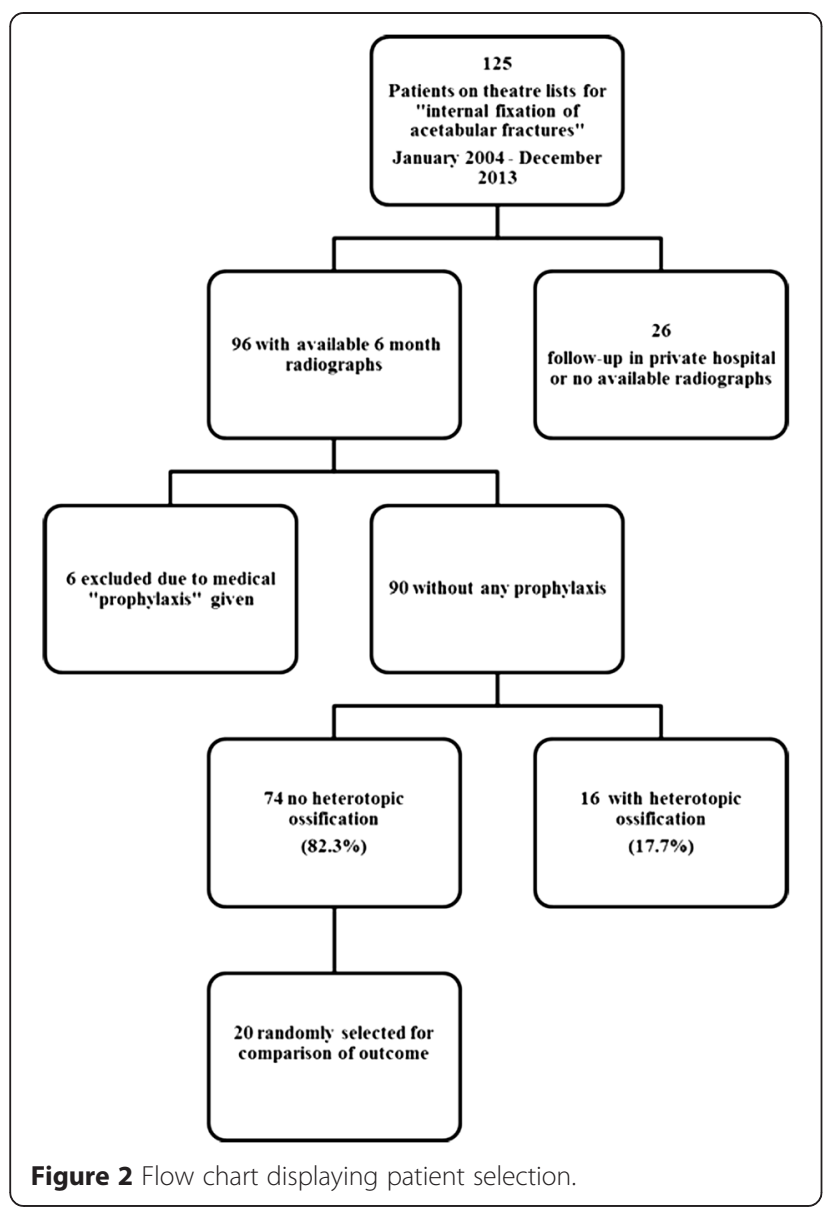

There were no significant differences in age, malefemale ratio and type of fracture in either group as well as between respondents and non-respondents. The HOOS in patients with $\mathrm{HO}$ and those in the control group were not statistically different (Table 3). Considering the grade of Brooker, patients suffering from Brooker grade II-IV HO had slightly lower HOOS (Figure 3). The characteristics and variables of the patients with $\mathrm{HO}$ are summarized in Table 4.

\section{Discussion}

We found a relatively low $\mathrm{HO}$ rate of $17.7 \%$ (12.2\% $\mathrm{HO}$ class $\geq 2$ ) in patients with internally fixed acetabular
Table 2 Unadjusted odds ratios for different predictors of heterotopic ossification

\begin{tabular}{lllll}
\hline & OR & \multicolumn{2}{l}{$\mathbf{9 5 \%}$ confidence interval } & $\boldsymbol{p}$ value $^{\mathbf{a}}$ \\
\hline TBI & 8.606 & 1.693 & 43.753 & $0.014^{*}$ \\
Spine injury & 1.788 & 0.539 & 5.933 & 0.258 \\
Male-female & 0.536 & 0.171 & 1.680 & 0.217 \\
Combined approach & 1.730 & 0.592 & 5.051 & 0.221 \\
T-type fracture & 0.951 & 0.425 & 2.132 & 0.561 \\
\hline
\end{tabular}

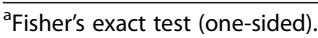

*Significant.

fractures who received no prophylaxis. Concomitant TBI was significantly correlated with a higher risk of $\mathrm{HO}$. The risk of $\mathrm{HO}$ in patients with combined anterior and posterior approach appeared to be lower than in patients with either anterior or posterior approach. Another trend observed was the slightly higher interval to treatment in the group of patients with HO. Surprisingly, the HOOS was not different between the $\mathrm{HO}$ and control group. Patients with $\mathrm{HO}$ graded II-IV according to the Brooker classification seemed to have slightly lower HOOS; however, this was not significant. Gender did not appear to influence occurrence of $\mathrm{HO}$. Concomitant TBI was the strongest predictor found for $\mathrm{HO}$.

Our overall rate of $\mathrm{HO}$ after internal fixation of acetabular fractures was low compared to the rates found in the literature $[1,2]$. It was reported to have an incidence as high as $90 \%$ in certain risk groups [18]. Karunakar et al., who summarized Brooker III-IV and excluded risk groups (TBI), found HO rates of $15.2 \%-19.4 \%$ (indomethacin vs. placebo) [19]. Another RCT compared HO in fracture patients treated with or without indomethacin prophylaxis had much higher $\mathrm{HO}$ rates of $47.4 \%$ and $56.8 \%$, respectively [2]. In this study, CT volumetry was used and detected more clinically irrelevant $\mathrm{HO}$ class I patients. A meta-analysis including 13 articles classifying $\mathrm{HO}$ found an overall incidence of 25.6\% [20]. A recent retrospective study in which none of the patients received prophylaxis found Brooker III-IV HO in $21 \%$ of patients with internal fixation of acetabular fractures [21]. Sagi et al. conducted a randomized controlled trial of patients treated with internal fixation of acetabular

Table 1 Different factors previously reported as risk factors for developing heterotopic ossification (HO)

\begin{tabular}{|c|c|c|c|c|}
\hline & $\mathrm{HO}(n=16)$ & No $\mathrm{HO}(n=74)$ & $p$ value & $95 \% \mathrm{Cl}$ \\
\hline Traumatic brain injury & $4(25 \%)$ & $3(4 \%)$ & $p=0.014^{*}$ & \\
\hline Spine injury & $5(31 \%)$ & $15(20.3 \%)$ & $p=0.337$ & \\
\hline Male-female ratio & 10:6 (69\%ぶ; 31\%우) & $56: 18(76 \%$ ‘ُ; 24\%우) & $p=0.351$ & \\
\hline Interval injury to treatment (days mean $\pm \mathrm{SD}$ ) & $9.188 \pm 4.35$ & $7.095 \pm 4.33$ & $p=0.074 ; \mathrm{EE}=-2$ & -4 to 0 \\
\hline Age (years mean $\pm S D$ ) & $39.875 \pm 17.32$ & $34.473 \pm 13.30$ & $p=0.281 ; \mathrm{EE}=-2$ & -13 to 4 \\
\hline
\end{tabular}

$E E$ effect estimate.

*Statistically significant; ㅇ female; ổmale; Fisher exact test (two-sided). 
Table 3 Hip disability and Osteoarthritis Outcome Score (HOOS)

\begin{tabular}{lllll}
\hline & Mean & Median & \pm SD & Range \\
\hline $\mathrm{HO}$ & 85.03 & 85.9 & \pm 10.52 & $61-100$ \\
Control & 86.04 & 95.5 & \pm 15.33 & $51-100$ \\
$p$ value & 0.525 & 0.220 & & \\
Estimate & & +4.25 & & \\
$95 \% \mathrm{Cl}$ & & -10.2 to +12.10 & & \\
\hline
\end{tabular}

fractures. Patients were randomly placed into a placebo group or one of the three groups receiving indomethacin prophylaxis for the duration of 3 days, 1 week, and 6 weeks, respectively [8]. They reported rates of symptomatic HO (Brooker III-IV) in 19\% of the placebo group and in $6 \%-31 \%$ of the three prophylactic groups and found no statistically significant reduction of symptomatic $\mathrm{HO}$ [8].

Patients with acetabular fractures and TBI had a much higher risk of $\mathrm{HO}$. This has been observed in previous studies, and the causal correlation has at least partially been explained [22-25]. Other traditional risk factors like gender, higher age and T-type fracture reported in several studies seemed less meaningful [26]. The present study shows a lower $\mathrm{HO}$ rate among patients with a more extensive combined anterior and posterior approach which could mean that this approach might have been beneficial to these patients with regard to HO. This may be due to a more thorough debridement and more anatomical reduction in those patients. Similarly to a study by Daum et al., a longer surgical delay was also found in patients who developed HO [27]. Mears et al. already found that a surgical delay of more than 11 days resulted in fewer anatomical reductions [28]. Maybe a

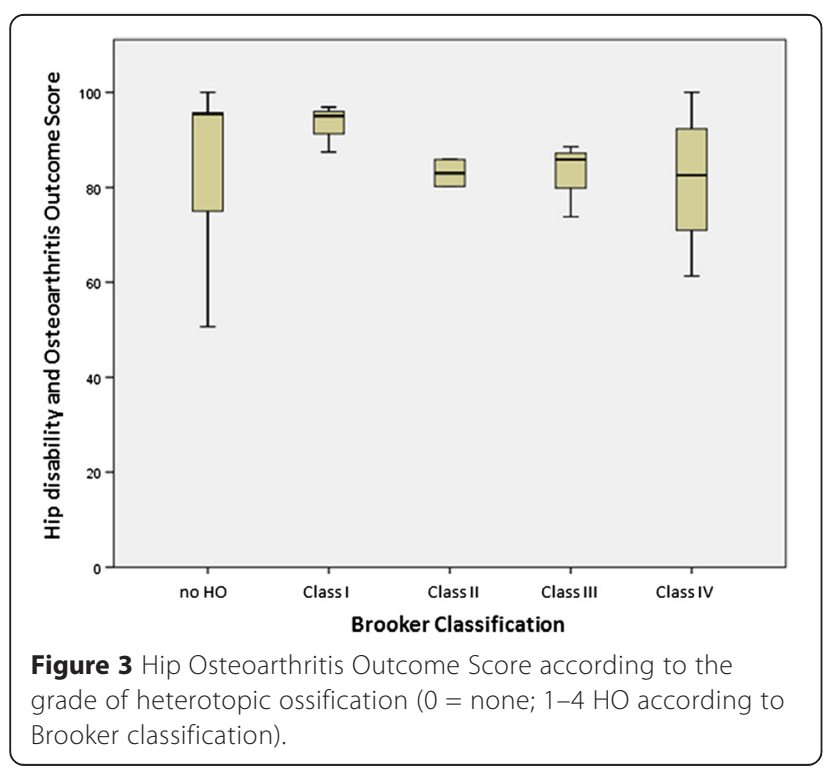

poor reduction rate in patients with longer surgical delay may have lead to a higher rate of $\mathrm{HO}$.

The outcome (HOOS) in this study was not much different in patients with HO. Only patients with class III or IV HO had slightly lower scores. McLaren already found that $\mathrm{HO}$ grade I (Brooker classification) has no clinical relevance. He found no association of grade I $\mathrm{HO}$ with decreased range of motion of the hip or any loss of function. Grade II was associated with a loss of range of motion of the hip without loss of function whereas functional impairment was found in grade III and IV HO [29]. The latter findings were not replicated in the present study results, and therefore, the clinical significance of $\mathrm{HO}$ for the outcome in acetabular fracture patients seems questionable.

In the light of this, the possible side effects of any prophylaxis should be considered. In the case of radioprophylaxis, one side effect is malignancy. Despite concluding that lifetime risk of radiation-induced cancer or infertility was insignificant, Oertel et al. found in a complex experimental model that prophylactic irradiation after fixation of an acetabular fracture in a 30-year-old patient results in a cumulative increased risk of solid cancer by $1 \%$ at the age of 65 [12]. Gastrointestinal and renal toxicity are known complications of treatment with NSAIDs $[10,11,13,14]$. In one study, compliance to medical prophylaxis was measured by control of indomethacin serum level and interviews. It was found that one third of the patients admittedly withdrew from taking indomethacin [19]. More than half of them did so because of side effects (13 compared to 1 in the placebo group). Two studies demonstrated that indomethacin prophylaxis significantly increases the risk of non-union in concomitant long-bone fractures, which are very common in acetabular fracture patients $[9,15]$.

The strength of our study is the relatively large number of acetabular fractures reviewed in one centre and treated by one surgical team. This minimizes the risk of bias through individual differences or techniques of the surgical treatment. None of the patients included received indomethacin or irradiation prophylaxis. The limitations of our study are that it is non-randomized. Bias is possible due to the retrospective design and some loss to follow-up due to missing radiographs. Despite the relatively large number of patients with internally fixed acetabular fractures included, the number of patients with $\mathrm{HO}$ was low and therefore limiting the statistical power of our study. However, a study with the largest cohort which examined the effect of prophylaxis against $\mathrm{HO}$ in patients with internally fixed acetabular fractures failed to gain sufficient statistical power [19].

Instead of new research emphasizing on the kind of prophylaxis needed, randomized controlled studies should question if there is an effect of prophylaxis at all. Possible 
Table 4 Characteristics and variables of patients with heterotopic ossification

\begin{tabular}{|c|c|c|c|c|c|c|c|c|c|}
\hline Age & Sex & Mechanism & Interval to treatment (days) & Surgical approach & TBI & Spinal trauma & AO-OTA classification & HOOS & Brooker class \\
\hline 42 & $f$ & MVA & 10 & Posterior & No & Spinal injury & A3 & 84.6 & 4 \\
\hline 27 & $\mathrm{~m}$ & MVA & 6 & Posterior & No & Spinal injury & $A 2$ & 95 & 1 \\
\hline 16 & f & MBA & 9 & Anterior & No & Nil & B2 & 87.5 & 1 \\
\hline 45 & $\mathrm{~m}$ & MVA & 4 & Posterior & No & Nil & $A 2$ & $x$ & 2 \\
\hline 62 & $\mathrm{~m}$ & MVA & 4 & Posterior & Yes & Spinal injury & $A 2$ & $x$ & 1 \\
\hline 22 & f & MVA & 6 & Posterior & No & Nil & A1 & $x$ & 1 \\
\hline 27 & $\mathrm{~m}$ & MBA & 5 & Posterior & No & $\mathrm{Nil}$ & $\mathrm{A} 1$ & 85.9 & 2 \\
\hline 74 & $f$ & MVA & 19 & Posterior & No & Nil & $A 2$ & $96.9^{\mathrm{a}}$ & 1 \\
\hline 47 & $f$ & MVA & 7 & Combined & No & Nil & B2 & 73.8 & 3 \\
\hline 42 & $F$ & MVA & 10 & Combined & No & $\mathrm{Nil}$ & B2 & 85.9 & 3 \\
\hline 35 & $\mathrm{~m}$ & MBA & 10 & Combined & Yes & Spinal injury & B2 & $x$ & 2 \\
\hline 67 & $\mathrm{~m}$ & MVA & 12 & Posterior & No & Nil & $A 2$ & 80.6 & 4 \\
\hline 52 & $\mathrm{~m}$ & MVA & 13 & Posterior & No & Nil & B2 & 88.6 & 3 \\
\hline 35 & $\mathrm{~m}$ & MVA & 16 & Posterior & No & Nil & B1 & $x$ & 2 \\
\hline 21 & $\mathrm{~m}$ & MVA & 5 & Posterior & Yes & Nil & $A 2$ & 61.3 & 4 \\
\hline 24 & $\mathrm{~m}$ & $\mathrm{MBA}$ & 11 & Posterior & Yes & Spinal injury & $\mathrm{A} 1$ & 100 & 4 \\
\hline
\end{tabular}

MBA motor bike accident, MVA motor vehicle accident, $T B I$ traumatic brain injury.

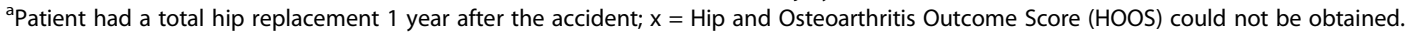

risk factors like surgical approach and surgeon's skills (invasiveness, thoroughness of debridement) could explain higher $\mathrm{HO}$ rates found in earlier studies. The influence of the time interval from injury to treatment should be considered, and early fixation without unnecessary delay should be aimed for. From our results, we cannot recommend giving prophylaxis against $\mathrm{HO}$ to patients after internal fixation of acetabular fractures. The question of whether prophylaxis has any beneficial effect for patients considered high risk for developing postoperative $\mathrm{HO}$, such as patients with TBI, is not yet proven.

\section{Conclusion}

A low rate of $\mathrm{HO}$ was found in this patient cohort that received no prophylaxis in comparison to $\mathrm{HO}$ rates described in other studies, which included similar patient groups that received prophylaxis. Traumatic brain injury was the only confirmed factor that increased the risk of $\mathrm{HO}$ significantly. Longer intervals from injury to internal fixation were observed in patients with $\mathrm{HO}$. An important measure to prevent $\mathrm{HO}$ might be to avoid unnecessary delay of internal fixation of the fractures. Based on our findings and the current literature, giving patients routine prophylaxis against $\mathrm{HO}$ after internal fixation of acetabular fractures is not recommended.

\section{Abbreviations}

HO: Heterotopic ossification; HOOS: Hip disability and Osteoarthritis Outcome Score; AP: Anterior-posterior; cGy: Centigray; NSAIDs: Non-steroidal antiinflammatory drugs.

\section{Competing interests}

The authors declare that they have no competing interests.

\section{Authors' contributions}

$\mathrm{DB}, \mathrm{RZ}$ and $\mathrm{DC}$ participated in the design. $\mathrm{DB}$ and $\mathrm{HR}$ participated in the data collection. DB, HR, DC and RZ performed the data analysis and interpretation. $\mathrm{DB}$ and $\mathrm{HR}$ participated in the manuscript writing. RZ and $\mathrm{DC}$ did the critical revision. All authors read and approved the final manuscript.

\section{Author details}

'Department of Orthopaedics and Trauma Surgery, Royal Perth Hospital, Perth, WA 6000, Australia. ${ }^{2}$ University of Western Australia, Crawley, WA 6009, Australia.

Received: 27 February 2015 Accepted: 27 April 2015

Published online: 09 May 2015

\section{References}

1. Kaempffe FA, Bone LB, Border JR. Open reduction and internal fixation of acetabular fractures: heterotopic ossification and other complications of treatment. J Orthop Trauma. 1991;5(4):439-45.

2. Matta JM, Siebenrock KA. Does indomethacin reduce heterotopic bone formation after operations for acetabular fractures? A prospective randomised study. J Bone Joint Surg. 1997;79(6):959-63.

3. Tonna EA, Cronkite EP. Autoradiographic studies of cell proliferation in the periosteum of intact and fractured femora of mice utilizing DNA labeling with H3-thymidine. Proc Soc Exp Biol Med. 1961;107:719-21.

4. Firoozabadi R, O'Mara TJ, Swenson A, Agel J, Beck JD, Routt M. Risk factors for the development of heterotopic ossification after acetabular fracture fixation. Clin Orthop Relat Res. 2014;472(11):3383-8.

5. Brooker AF, Bowerman JW, Robinson RA, Riley Jr LH. Ectopic ossification following total hip replacement. Incidence and a method of classification. J Bone Joint Surg Am. 1973;55(8):1629-32.

6. Thomas BJ. Heterotopic bone formation after total hip arthroplasty. Orthop Clin North Am. 1992:23(2):347-58

7. Macfarlane RJ, Ng BH, Gamie Z, El Masry MA, Velonis S, Schizas C, et al. Pharmacological treatment of heterotopic ossification following hip and acetabular surgery. Expert Opin Pharmacother. 2008;9(5):767-86. 
8. Sagi HC, Jordan CJ, Barei DP, Serrano-Riera R, Steverson B. Indomethacin prophylaxis for heterotopic ossification after acetabular fracture surgery increases the risk for nonunion of the posterior wall. J Orthop Trauma. 2014;28(7):377-83.

9. Burd TA, Hughes MS, Anglen JO. Heterotopic ossification prophylaxis with indomethacin increases the risk of long-bone nonunion. J Bone Joint Surg (Br). 2003;85(5):700-5.

10. Clive DM, Stoff JS. Renal syndromes associated with nonsteroidal antiinflammatory drugs. N Engl J Med. 1984;310(9):563-72.

11. Oates JA, FitzGerald GA, Branch RA, Jackson EK, Knapp HR, Roberts 2nd L Clinical implications of prostaglandin and thromboxane A2 formation (1). N Engl J Med. 1988;319(11):689-98.

12. Oertel S, Schneider U, Keel M, Lutolf UM, Bosshard G. Prophylaxis of heterotopic ossification in patients sedated after polytrauma: medical and ethical considerations. Strahlenther Onkol. 2008:184(4):212-7.

13. Schneider V, Levesque LE, Zhang B, Hutchinson T, Brophy JM. Association of selective and conventional nonsteroidal antiinflammatory drugs with acute renal failure: a population-based, nested case-control analysis. Am J Epidemiol. 2006;164(9):881-9.

14. Wolfe MM, Lichtenstein DR, Singh G. Gastrointestinal toxicity of nonsteroidal antiinflammatory drugs. N Engl J Med. 1999;340(24):1888-99.

15. Vuolteenaho K, Moilanen T, Moilanen E. Non-steroidal anti-inflammatory drugs, cyclooxygenase-2 and the bone healing process. Basic Clin Pharmacol Toxicol. 2008;102(1):10-4.

16. Klassbo M, Larsson E, Mannevik E. Hip disability and osteoarthritis outcome score. An extension of the Western Ontario and McMaster Universities Osteoarthritis Index. Scand J Rheumatol. 2003;32(1):46-51.

17. Nilsdotter AK, Lohmander LS, Klassbo M, Roos EM. Hip disability and osteoarthritis outcome score (HOOS) — validity and responsiveness in total hip replacement. BMC Musculoskelet Disord. 2003;4:10.

18. Bosse MJ, Poka A, Reinert CM, Ellwanger F, Slawson R, McDevitt ER. Heterotopic ossification as a complication of acetabular fracture. Prophylaxis with low-dose irradiation. J Bone Joint Surg Am. 1988;70(8):1231-7.

19. Karunakar MA, Sen A, Bosse MJ, Sims SH, Goulet JA, Kellam JF. Indometacin as prophylaxis for heterotopic ossification after the operative treatment of fractures of the acetabulum. J Bone Joint Surg. 2006;88(12):1613-7.

20. Giannoudis PV, Grotz MR, Papakostidis C, Dinopoulos H. Operative treatment of displaced fractures of the acetabulum. A meta-analysis. J Bone Joint Surg. 2005;87(1):2-9.

21. Griffin SM, Sims SH, Karunakar MA, Seymour R, Haines N. Heterotopic ossification rates after acetabular fracture surgery are unchanged without indomethacin prophylaxis. Clin Orthop Relat Res. 2013;471(9):2776-82.

22. Gautschi OP, Cadosch D, Frey SP, Skirving AP, Filgueira L, Zellweger R. Serum-mediated osteogenic effect in traumatic brain-injured patients. ANZ J Surg. 2009;79(6):449-55

23. Gautschi OP, Toffoli AM, Joesbury KA, Skirving AP, Filgueira L, Zellweger R. Osteoinductive effect of cerebrospinal fluid from brain-injured patients. J Neurotrauma. 2007;24(1):154-62

24. Simonsen LL, Sonne-Holm S, Krasheninnikoff M, Engberg AW. Symptomatic heterotopic ossification after very severe traumatic brain injury in 114 patients: incidence and risk factors. Injury. 2007;38(10):1146-50.

25. Toffoli AM, Gautschi OP, Frey SP, Filgueira L, Zellweger R. From brain to bone: evidence for the release of osteogenic humoral factors after traumatic brain injury. Brain Inj. 2008;22(7-8):511-8.

26. Ghalambor N, Matta JM, Bernstein L. Heterotopic ossification following operative treatment of acetabular fracture. An analysis of risk factors. Clin Orthop Relat Res. 1994;305:96-105.

27. Daum WJ, Scarborough MT, Gordon Jr W, Uchida T. Heterotopic ossification and other perioperative complications of acetabular fractures. J Orthop Trauma. 1992;6(4):427-32.

28. Mears DC, Velyvis JH, Chang CP. Displaced acetabular fractures managed operatively: indicators of outcome. Clin Orthop Relat Res. 2003;407:173-86.

29. McLaren AC. Prophylaxis with indomethacin for heterotopic bone. After open reduction of fractures of the acetabulum. J Bone Joint Surg Am. 1990;72(2):245-7

\section{Submit your next manuscript to BioMed Central and take full advantage of:}

- Convenient online submission

- Thorough peer review

- No space constraints or color figure charges

- Immediate publication on acceptance

- Inclusion in PubMed, CAS, Scopus and Google Scholar

- Research which is freely available for redistribution 